\title{
Introduction of Teaching Associates in Maxillofacial Surgery - the Renaissance of a Teaching Method
}

\author{
Sebastian Herbert Hoefer ${ }^{1}$, Jan Mrosek ${ }^{1}$, Jonas Lorenz ${ }^{1}$, Bernd Bender ${ }^{2}$, Marius Theis ${ }^{1}$, Jasmina Sterz ${ }^{2}$, \\ Christina Stefanescu ${ }^{2}$, Miriam Ruesseler ${ }^{2}$ and Robert Sader ${ }^{1}$ \\ ${ }^{1}$ Department of Oral, Cranio-Maxillofacial, and Facial Plastic Surgery, University Hospital Frankfurt, Goethe \\ University, Theodor-Stern-Kai 7, 60590 Frankfurt, Germany, Head of department: Prof. Dr. Dr. R. Sader \\ ${ }^{2}$ Department of Trauma, Hand, and Reconstructive Surgery, University Hospital Frankfurt, Goethe University, \\ Theodor-Stern-Kai 7, 60590 Frankfurt, Germany, Head of department: Prof. Dr. I. Marzi \\ Email: shoefer@em.uni-frankfurt.de
}

\begin{abstract}
Background: One of the greatest challenges in education is ensuring all students acquire competencies and retain those competencies over a long period of time. At the same time, the correct execution of practical skills is highly necessary. This study investigates the role of feedback reception stemming from teaching associates. Materials and Methods: All fourth year dental students at a German university who completed their internship in cmf-surgery participated. The students were randomized into two groups. Student's competency directly after intervention and three months after the training was measured. Results: A total of 39 students were included. At both time points, the intervention group performed significantly better than the control group $(\mathrm{p}=<.001)$. Conclusion: The integration of teaching associates to instruct complex practical skills, has a significant positive effect on retaining transferred information on a short- and long-term basis.
\end{abstract}

Keywords: Dental education, medical education, teaching associates, complex practical skills, long term benefit, multimodal feedback, education in cmf-surgery

\section{Introduction}

The modernization and harmonization of dental education is sought in both Germany and all of Europe (Cowpe, Plasschaert, Harzer, Vinkka-Puhakka \& Walmsley, 2010), (Hugger, Hugger \& Kordass, 2011), (Shanley, Dowling, Claffey \& Nattestad, 2002). After a long struggle, the National Competence Based Catalogue of Learning Objectives for Undergraduate Dental Education (NKLZ) was implemented in Germany (Fischer, Bauer, Mohn \& Projektgruppe, 2015). There is a general agreement, that the path should lead away from teaching methods where information is just handed down to the students. A more effective and motivational style of teaching and learning can create a positive impact on the entire course of study (Fabry, 2008), (Hugger et al., 2011), (Schonwetter, Reynolds, Eaton \& De Vries, 2010). In this regard, a crucial factor will be the competence-based education of future health professionals (Chuenjitwongsa, Oliver \& Bullock, 2016).

The management of daily clinical practice is significantly influenced by the level of expertise regarding practical skills (Goodwin, 1995), not only in medicine but even more so in dentistry (Chestnutt \& Gibson, 2007), (Sweet, Wilson \& Pugsley, 2008). The fact that a vast range of technical to psychosocial skills are required (Sweet et al., 2008) demands profound practical clinical competence and henceforth requires university curricula to focus the training of their students on those competencies needed. Furthermore, during undergraduate medical and dental training, it is imperative that specific skills such as placing iv-lines, performing sutures, etc. are mastered to a high level by all students because medical and dental students undertake those invasive and irreversible procedures on a daily clinical basis (Chuenjitwongsa et al., 2016).

The transfer of practical skills may appear simple at first sight, since it often resembles a plain student-master-relationship. However, looked at in more detail it soon becomes evident that the process of acquiring those skills and applying them on a daily basis is multidimensional and complex in nature, and combines various levels of competence. The complexity of manual skills such as physical examination or basic invasive procedures is demanding for the learner. Furthermore, the lack of training 
of the instructors themselves and their lack of special educational qualifications places a great burden on adequate medical and dental education. To many times the instructors just plainly apply the teaching methods which were in place when they were taught as students. Often these methods are applied with personal modifications and improvisation yet without critical reflection (Conn, 2002), (Gibson \& Campbell, 2000), (Godfrey, Dennick \& Welsh, 2004), (McLeod, Steinert, Meagher \& McLeod, 2003), (Wall \& McAleer, 2000), (Wilkerson \& Irby, 1998).

There is no universal consensus in regard to what teaching methods deliver the most sustainable results as well as in what context knowledge and skills are best transferred. Several approaches have been described previously such as mastery learning, mental training or peer teaching (Beyer, 2000), (Immenroth, 2005), (Udani, Macario, Nandagopal, Tanaka \& Tanaka, 2014). Studies have shown that feedback plays an essential role regarding the mediation of basic skills (Porte, Xeroulis, Reznick \& Dubrowski, 2007), (Xeroulis et al., 2007). However, there is a lack of studies that focus on the long-term effect of teaching those skills. Yet the long-term impact is crucial, as both knowledge and practical skills deteriorate if they are not applied continuously (Arthur, Bennett, Stanush \& McNelly, 1998), (Madden, 2006) or if they are not sufficiently embedded within the memory of the learner. If embedding cannot be assured, a mismatch arises between individual competence and the competence required to execute a task or skill (Chuenjitwongsa et al., 2016).

Barrows introduced another possibility for transferring skills in 1964 (Barrows \& Abrahamson, 1964). He was one of the first to apply the concept of patient simulation within clinical education. This concept was first used in neurological training and then extended to various other medical specialties (Barrows, 1993).

Teaching Associates / Teaching Assistants (TA) reflect a major educational milestone. Examination techniques are taught in person by the TAs (Parle, Ross \& Coffey, 2012). This method is especially common in gynecology, urology, and proctology (Barley, Fisher, Dwinnell \& White, 2006), (Parle et al., 2012), (Siebeck et al., 2011), where "students receive immediate feedback on their skills and practice until they get it right" (Barley et al., 2006). This is, according to our understanding, an ideal mechanism for knowledge transfer that can be applied to other examination techniques. The conceptual framework of the method is closely aligned to the guidance hypothesis. Furthermore, TAs "are trained to teach exams in a standardized manner and do not have an experience base, or bias, like physicians to adapt or modify the exam" (Barley et al., 2006). For all the above mentioned reasons, we decided to use TAs in our maxillofacial class to facilitate knowledge and skills transfer for a structured head and skull examination.

The aim of the study was to compare two teaching methods for skills transfer of a structured head and skull examination, and to determine which method had the greatest short- and long-term success in transferring complex practical clinical skills. The underlying hypothesis states that lessons with TAs produce the best results on a short- and long-term basis for successful transfer of a haptic competence.

\section{$2 \quad$ Material and Methods}

The study was reviewed by the ethical committee of the University Hospital of Frankfurt (JohannWolfgang Goethe University) and it was stated, that no further approval was required. The study was conducted according to the Declaration of Helsinki.

\subsection{Participants}

All fourth year dental students completing their obligatory internship in cranio-maxillofacial surgery (cmf-surgery; consisting of a practical skills training (PST) and a one-week clerkship (Landes et al., 2014) were invited to participate. The students were informed about the type and process of the study and gave their written) consent for participation (which could be withdrawn at any time, including having their performance video recorded.

In addition, the instructors, TAs, and standardized patients also signed informed consent forms to participate in the study and provided permission to be videotaped in the examination.

\subsection{Instructors and Teaching Associates}


All instructors (including the TAs) participated in a training session (180 min) prior to the start of the course. The training included exercises in giving feedback and performing the "head and skull examination" as well as the "ligature of 8".

As instructors we appointed senior physicians from the Department of Cranio-Maxillofacial Surgery (CMF-Surgery) and as TAs we chose advanced students (medical as well as dental students). The students were paid $10 €$ /hour.

\subsection{Randomization and Intervention}

All students were randomized into two groups via balanced simple randomization. Balanced simple randomization aimed to reach nearly equal group sizes and to provide imbalance of gender between the groups. The control group consists of $n=19$ students and the intervention group of $n=20$ students.

The entire PST lasts $480 \mathrm{~min}$ and has a detailed time schedule (Fig. 1) and a training manual, including a detailed description of all items included in the examination. The estimated time for teaching the examination technique was $90 \mathrm{~min}$. For both groups, the structured head and skull examination took place in the second - practical - part of the PST.

The control group received lessons provided by an instructor from the department of cmf-surgery. The sub-lecture "head and skull examination" included a structured power point presentation that covered examination techniques, a demonstration of the examination technique using a student, and practice performing the examination in a one-on-one peer-based context with supervision and feedback from the instructor.

The intervention group was taught by a TA and included the theoretical lessons and demonstration described above. However, there was no one-on-one peer exercise. Examination practice with peers was replaced with an examination exercise performed on the TA using the same time frame as the control group. To stay in the time limit of the course, two TAs were deployed to lead the examination exercise.

\section{$2.4 \quad$ Feedback}

The intervention group received feedback in terms of guidance theory by the TAs. During the exercise period, the TAs used concurrent visuohaptic multimodal feedback.

Based on the definitions by (Sigrist, Rauter, Riener \& Wolf, 2013) we defined "concurrent visuohaptic multimodal feedback" as an augmented feedback, meaning a feedback that is provided by the TA during the exercise. Visuohaptic implies that the feedback-information transferred by speech is also strongly perceived in a visual and haptic manner by the student.

The control group also received feedback from the instructor that was formulated using guidance theory. As with the intervention group, the control group's feedback was also concurrent, but they received no direct feedback from the examination subject.

After the first assessment, the control and intervention groups both received one final round of feedback from standardized patients.

To have a second data collection regarding the effect of the course and specifically the TA feedback, a second practical skill (ligature of 8) was taught and examined, parallel and according to the same framework. The difference from the head and skull examination was that the ligature of the jaw was not performed with the TA but rather with a phantom model (frasaco ANA-4 + P6/4, frasaco Tettnang Germany). Hence, it could not be expected that the immediate feedback from the TA during the procedure would have a significant effect.

\subsection{Assessment}

At the end of the PST, all students participated in a formative videotaped assessment in the context of an OSCE (objective structured clinical examination) station. The examination was performed on a standardized patient in the case of the head and skull examination and on a phantom model in the case of the ligature of 8 (frasaco ANA-4 + P6/4, frasaco Tettnang Germany); both examinations for each student were recorded.

The videos were then shown to three examiners who were blinded to group assignment. All three raters participated in the mandatory examiner training given to all faculty, which consists of a $30 \mathrm{~min}$ 
online tutorial and a 60 min simulation of a video rating.

The raters assessed the performance of the students using the standardized checklists (Fig. 2; Fig. 3) used for head and skull examinations and the ligature of 8 . The checklist has been used in OSCEs since 2009 and has been described previously (Höfer, Schuebel, Sader \& Landes, 2013) and the validation process of the checklist was presented at the annual congress of the German Society for CranioMaxillofacial Surgeons in 2009.

The raters were a fifth-year dental student, a second-year resident doctor (i.e., beginning clinical training), and an attending doctor in the department of cmf-surgery. All examiners rated the video material in an independent manner and assessed the students according to the OSCE checklist.

Three months after the PST and the internship, the cmf-OSCE took place as an obligatory, but formative exam. The entire exam was videotaped (both head and skull examination and ligature of 8). The videos were shown to the same three examiners, who rated the videos in the same independent manner and with the same checklist as after the PST.

Furthermore, we used a structured questionnaire to obtain information from students about their duration of self-study and type of preparation used for the final OSCE exam; both the head and skull examination and the ligature of 8 were included in the questionnaire.

\subsection{Statistics}

Statistical analyses were performed using SPSS version 19.0 (IBM, Armonk, USA). If a Gaussian distribution was not present in the data, then non-parametric test methods were applied. If a Gaussian distribution was present, then parametric test methods were applied. To test for significant mean differences, the averages of both groups were analyzed with the parametric t-test or with the nonparametric Kolmogorov-Smirnov-test and the non-parametric Mann-Whitney U-test. The Cohen's d effect size was calculated for the mean difference between both groups. As a measurement of correlation, Pearson correlations and correlations via Kendall's Tau-b were calculated.

\section{$3 \quad$ Results}

\subsection{General Results}

A total of 39 students were included in this study; $66.6 \%$ were female $(\mathrm{n}=26)$ and $33.3 \%$ were male (n $=13)$. This reflects exactly the gender distribution of the class of that semester.

Of the 39 students, 19 were assigned to the control group and 20 to the intervention group (TA group). All students agreed to be videotaped.

\subsection{Objective Structured Clinical Examination: Checklist Head and Skull Examination:}

With regards to practical clinical skills (GSU), the TA group achieved significantly higher ratings from all raters than the control group at both time points (time point $1, \mathrm{p}=<.001$, time point $2 \mathrm{p}=<.001$; Fig. 4). The effect size (Cohens $d$ (Cohen 1988)) at time point 1 was $d=1.485$ and $d=1.153$ at time point 2 .

\subsection{Objective Structured Clinical Examination: Checklist Ligature of 8:}

With regards to practical clinical skills (ligature of 8), at both time points the TA group did not differ significantly from the control group (time point $1 \mathrm{p}=.700, \mathrm{~d}=0.075$; time point $2 \mathrm{p}=.530, \mathrm{~d}=.116$; Fig. 4).

\subsection{Results by Gender}

At time point 1, male participants achieved slightly higher ratings for both skills, however this difference was not significant $(\mathrm{p}=.697$ for the ligature of 8 and $\mathrm{p}=.173$ for head and skull examination, respectively). At time point 2 female students achieved slightly higher results, but these 
differences were likewise not significant $(\mathrm{p}=.834$ for the ligature of 8 and $\mathrm{p}=.831$ for head and skull examination, respectively).

\subsection{Examiners}

The inter-rater reliability (IRR) was .563 for the head and skull examination at time point 1 and .606 at time point 2. For the ligature of 8 , the IRR was .594 (time point 1) and .547 (time point 2), respectively.

\subsection{Duration of Study}

The structured questionnaire regarding the duration of study and the kind of preparation was answered by all 39 students (19 control group, 20 TA group). A significant difference was not observed $(\mathrm{p}=.915)$. Analysis of study time with respect to gender also showed no significant differences $(\mathrm{p}=.867)$.

\section{Discussion}

To the best of our knowledge, no study to date has analyzed the use of TAs in dental education until now. The few that have been published in this regard have analyzed the teaching of manual skills with a focus on urogenital and anal examination (Jha, Setna, Al-Hity, Quinton \& Roberts, 2010). Barley (Barley et al., 2006) described the use of TAs in multiple clinical disciplines, yet studies investigating the use of TAs in other contexts are rare.

Additionally, there is a severe lack of studies that approach the question of long-term efficacy of the use of TAs. In a previous study we analyzed the long-term effect of TAs and were able to demonstrate that TAs can be deployed very successfully for the transfer of clinical skills. However, in the above mentioned study, the second time point took place as a summative exam. This presents a major limitation of the former study, as this exam is more prone to bias since it is essential for completing the semester. Second, the rating of the two time points was conducted differently, representing another place where bias could also have been introduced into the study.

Our current study shows that the students who were taught the head and skull examination by a TA achieved significantly better results than their counterparts in the control group who received conventional teaching.

We also believe that the main reason for the success of the TA group in learning the head and skull examination technique lies in the continuous and immediate visuohaptic multimodal feedback they received on their examination techniques, where the feedback happens just as they are performing their examination. This assumption is supported by Sigrist and Hatala (Hatala, Cook, Zendejas, Hamstra \& Brydges, 2014), (Sigrist et al., 2013). The results of Hattie und Timperley (Hattie \& Timperley, 2007) are also in accordance with the findings of our study. In their meta-analysis of similarly structured feedback, they likewise described effect sizes $>1$. The opportunity to get the feedback of the correct haptic impression of the examination technique cannot be achieved in a peer exercise, even under supervision.

The effect of this type of feedback becomes even clearer when the two types of skills assessed in this study are compared with each other. Neither the TA group nor the control group showed any advantage regarding the ligature of 8 skill, even though continuous immediate feedback was given during this module. It was the visuohaptic component of direct touching that was missing in the feedback they were given.

The instructor effect may be one further reason why the TA group showed superior results to the control group. TAs are trained to teach examination techniques without diverging from the teaching manual. Instructors in clinic face the dilemma, due to their clinical expertise, of conceptualizing their teaching in a more free and personal way, despite the existence of a teaching manual. But this hypothesis becomes refuted by comparing both skills since the teaching of a ligature of 8 by faculty members or TAs did not make a difference.

The results from time point 2 highlight that students taught by TAs remain significantly better at performing the skills than those in the control group, even after 3 months. Even in a formative exam, a measured effect size $>1$ can be shown. To our knowledge, this is the first study to demonstrate that 
using TAs in dental education to provide instruction on examination techniques produces significantly better results, and that this difference persists for months (Fig. 4). This proves the efficiency of this method, especially for achieving long-term results.

These results clearly support the research hypotheses that short- and long-learning success is higher when TAs are used for complex practical skills.

Our study has several limitations. First, the IRR lies between .547 und .606. One might suggest that the results would change when a higher IRR is in place. However, if one applies Schmidt's definition (Schmidt, 1997), acceptable IRR lies between 0.5 (moderate) and 0.7 (strong). Hence, the values can be judged as useful.

Another limitation is the fact that the study was designed for a single center. Other universities might have different conditions that would prevent the findings from generalizing to their student populations.

Furthermore the study only shows the use of TAs for one specific skill. In the future transferability in relation to other skills should be investigated.

Finally, also the economic side must be addressed. Even in a university hospital setting financial expenditures are always under close scrutiny. In this regard, patient care and teaching are two competing actors. Two advantages become apparent when one has the ability to apply teaching associates: $1^{\text {st }}$ - In the local remuneration structure (two student TAs cost $10 € /$ hour each whereas the faculty member costs $50 €$ /hour), it is possible to save up to $60 \%$ of the costs by using TAs. $2^{\text {nd }}-$ using TAs creates time for the medical faculty.

\section{Conclusion}

The introduction of TAs as an integral part of modern medical and dental education to transfer complex practical skills is an effective didactic method that has proven to be highly beneficial for short- and long-term learning success. This method can be applied to almost all clinical skills that are directly performed on patients. Furthermore, the use of TAs has a positive economic effect in the sense of cost reduction and sustainable allocation of financial resources. For this reason, the use of TAs provides a promising platform for the competence-based education for students in future.

\section{References}

1. W. J. Arthur, W. J. Bennett, P. L. Stanush \& T. L. McNelly. (1998). Factors that influence skill decay and retention: a quantitative review and analysis. Hum Perform, 11, 57-101.

2. G. E. Barley, J. Fisher, B. Dwinnell \& K. White. (2006). Teaching foundational physical examination skills: study results comparing lay teaching associates and physician instructors. Acad Med, 81(10 Suppl), 95-97.

3. H. S. Barrows.(1993). An overview of the uses of standardized patients for teaching and evaluating clinical skills. AAMC. Acad Med, 68(6), 443-451.

4. H. S. Barrows \& S. Abrahamson. (1964). The Programmed Patient: A Technique for Appraising Student Performance in Clinical Neurology. J Med Educ, 39, 802-805.

5. L. Beyer.(2000). Mentales Training in der Weiter-und Fortbildung "Manuelle Medizin". Manuelle Medizin, 3(38), 183-187.

6. I. G. Chestnutt \& J. Gibson. (2007). Clinical dentistry. London: Elsevier Health Sciences.

7. S. Chuenjitwongsa, R. G. Oliver \& A. D. Bullock. (2016). Competence, competency-based education, and undergraduate dental education: a discussion paper. Eur J Dent Educ. doi:10.1111/eje.12213

8. J. J. Conn. (2002). What can clinical teachers learn from Harry Potter and the Philosopher's Stone? Med Educ, 36(12), 1176-1181.

9. J. Cowpe, A. Plasschaert, W. Harzer, H. Vinkka-Puhakka \& A. D. Walmsley. (2010). Profile and competences for the graduating European dentist - update 2009. Eur J Dent Educ, 14(4), 193-202. doi:10.1111/j.16000579.2009.00609.x

10.G. Fabry. (2008). Medizindidaktik - ein Handbuch für die Praxis. Bern: Huber.

11.M. R. Fischer, D. Bauer, K. Mohn \& N. Projektgruppe. (2015). Finally finished! National Competence Based Catalogues of Learning Objectives for Undergraduate Medical Education (NKLM) and Dental Education (NKLZ) ready for trial. GMS Z Med Ausbild, 32(3), Doc35. 
12.D. R. Gibson \& R. M. Campbell. (2000). Promoting effective teaching and learning: hospital consultants identify their needs. Med Educ, 34(2), 126-130.

13.J. Godfrey, R. Dennick \& C. Welsh. (2004). Training the trainers: do teaching courses develop teaching skills? Med Educ, 38(8), 844-847. doi:10.1111/j.1365-2929.2004.01896.x

14.J. Goodwin. (1995). The importance of clinical skills. BMJ, 310(6990), 1281-1282.

15.R. Hatala, D. A. Cook, B. Zendejas, S. J. Hamstra \& R. Brydges. (2014). Feedback for simulation-based procedural skills training: a meta-analysis and critical narrative synthesis. Adv Health Sci Educ Theory Pract, 19(2), 251-272. doi:10.1007/s10459-013-9462-8

16.J. Hattie \& H. Timperley. (2007). The Power of Feedback. Review of Educational Research, 77(1), 81-112. doi:10.3102/003465430298487.

17.S. H. Höfer, F. Schuebel, R. Sader \& C. Landes. (2013). Development and implementation of an objective structured clinical examination (OSCE) in CMF-surgery for dental students. J Craniomaxillofac Surg, 41(5), 412416. doi:10.1016/j.jcms.2012.11.007

18.A. Hugger, S. Hugger \& B. Kordass. (2011). [Dental education in Germany: new concepts for the dental curriculum]. Bundesgesundheitsblatt Gesundheitsforschung Gesundheitsschutz, 54(9), 1046-1051. doi:10.1007/s00103-011-1328-8

19.M. B. Immenroth, T.; Brenner, J.; Kemmler, R.; Nagelschmidt, M.; Eberspächer, H.; Troidl, H. (2005). Mentales Training in der Chirurgie. Retrieved from BDC Online - Information und Service für Deutsche Chirurgen website: http://www.bdc.de/index_level3.jsp?documentid=C957DF3D04C412D3C1256F95004DB659\&form=Dokumente \&parent=1D87D75F022E4C64C2256FC5004FD0E7\&menu_id=B1CFAFC0D2CA0CD5C1257323004D1147\&cate gory=ARCHIV-WEITERBILDUNG-CHIRURGISCHES\%20TRAINING

20.V. Jha, Z. Setna, A. Al-Hity, N. D. Quinton \& T. E. Roberts. (2010). Patient involvement in teaching and assessing intimate examination skills: a systematic review. Med Educ, 44(4), 347-357. doi:10.1111/j.13652923.2009.03608.x

21.C. A. Landes, S. Hoefer, F. Schuebel, A. Ballon, A. Teiler, A. Tran, . . R. Rader. (2014). Long-term prospective teaching effectivity of practical skills training and a first OSCE in cranio maxillofacial surgery for dental students. J Craniomaxillofac Surg, 42(5), e97-104. doi:10.1016/j.jcms.2013.07.004

22.C. Madden. (2006). Undergraduate nursing students' acquisition and retention of CPR knowledge and skills. Nurse Educ Today, 26(3), 218-227. doi:10.1016/j.nedt.2005.10.003.

23.P. J. McLeod, Y. Steinert, T. Meagher \& A. McLeod. (2003). The ABCs of pedagogy for clinical teachers. Med Educ, 37(7), 638-644.

24.J. Parle, N. Ross \& F. Coffey. (2012). Clinical teaching associates in medical education: the benefits of certification. Clin Teach, 9(5), 275-279. doi:10.1111/j.1743-498X.2012.00585.x

25.M. C. Porte, G. Xeroulis, R. K. Reznick \& A. Dubrowski. (2007). Verbal feedback from an expert is more effective than self-accessed feedback about motion efficiency in learning new surgical skills. Am J Surg, 193(1), 105-110. doi:10.1016/j.amjsurg.2006.03.016

26.R. C. Schmidt. (1997). Managing Delphi surveys using nonparametric statistical techniques. Decision Sciences, $28(3), 763-774$.

27.D. J. Schonwetter, P. A. Reynolds, K. A. Eaton \& J. De Vries. (2010). Online learning in dentistry: an overview of the future direction for dental education. J Oral Rehabil, 37(12), 927-940. doi:10.1111/j.13652842.2010.02122.x

28.D. B. Shanley, P. A. Dowling, N. Claffey \& A. Nattestad. (2002). European convergence towards higher standards in dental education: the DentEd Thematic Network Project. Med Educ, 36(2), 186-192.

29.M. Siebeck, B. Schwald, C. Frey, S. Roding, K. Stegmann \& F. Fischer. (2011). Teaching the rectal examination with simulations: effects on knowledge acquisition and inhibition. Med Educ, 45(10), 1025-1031. doi:10.1111/j.1365-2923.2011.04005.x

30.R. Sigrist, G. Rauter, R. Riener \& P. Wolf. (2013). Augmented visual, auditory, haptic, and multimodal feedback in motor learning: a review. Psychon Bull Rev, 20(1), 21-53. doi:10.3758/s13423-012-0333-8

31.J. Sweet, J. Wilson and L. Pugsley. (2008). Chairside teaching and the perceptions of dental teachers in the UK. Br Dent J, 205(10), 565-569. doi:10.1038/sj.bdj.2008.983

32.A. D. Udani, A. Macario, K. Nandagopal, M. A. Tanaka \& P. P. Tanaka. (2014). Simulation-based mastery learning with deliberate practice improves clinical performance in spinal anesthesia. Anesthesiol Res Pract, 2014, 
659160. doi:10.1155/2014/659160

33.D. Wall \& S. McAleer. (2000). Teaching the consultant teachers: identifying the core content. Med Educ, 34(2), 131-138.

34.L. Wilkerson \& D. M. Irby. (1998). Strategies for improving teaching practices: a comprehensive approach to faculty development. Acad Med, 73(4), 387-396.

35.G. J. Xeroulis, J. Park, C. A. Moulton, R. K. Reznick, V. Leblanc \& A. Dubrowski. (2007). Teaching suturing and knot-tying skills to medical students: a randomized controlled study comparing computer-based video instruction and (concurrent and summary) expert feedback. Surgery, 141(4), 442-449. doi:10.1016/j.surg.2006.09.012

\section{Appendix}

\begin{tabular}{|c|c|c|c|}
\hline Duration & $\underline{\text { Content }}$ & Methods & Protagonists \\
\hline $\begin{array}{l}30 \mathrm{~min} \\
(30 \mathrm{~min}) \\
\end{array}$ & $\begin{array}{l}\text { Welcome, Introduction of the internship, } \\
\text { Presentation of the learning goals }\end{array}$ & Frontal & Lecturer \\
\hline $\begin{array}{l}\mathbf{1 5} \min \\
(45 \mathrm{~min})\end{array}$ & $\begin{array}{l}\text { How to act correct in the operation } \\
\text { theatre }\end{array}$ & PPT & Lecturer \\
\hline $\begin{array}{l}\mathbf{1 5} \mathbf{m i n} \\
(60 \mathrm{~min}) \\
\end{array}$ & Introduction in cranial examination & PPT & Lecturer \\
\hline $\begin{array}{l}90 \mathrm{~min} \\
(150 \mathrm{~min})\end{array}$ & Practical exercise: cranial examination & $\begin{array}{l}\text { Examination with TA or } \\
\text { peer tandem }\end{array}$ & $\begin{array}{l}\text { Lecturer/Teaching } \\
\text { assistant and students }\end{array}$ \\
\hline $\begin{array}{l}10 \mathrm{~min} \\
(160 \mathrm{~min})\end{array}$ & Break & & \\
\hline $\begin{array}{l}40 \mathrm{~min} \\
(200 \mathrm{~min})\end{array}$ & Cranial traumatology & $\begin{array}{l}\text { Case study: } \\
\text { Lower jaw fractures } \\
\text { Mid-face fractures } \\
\end{array}$ & Lecturer/students \\
\hline $\begin{array}{l}5 \text { min } \\
(205 \mathrm{~min})\end{array}$ & Break & & \\
\hline $\begin{array}{l}\mathbf{3 0} \min \\
(235 \mathrm{~min})\end{array}$ & Odontogenic Inflammation & $\begin{array}{l}\text { Case study: } \\
\text { Mild and severe infections }\end{array}$ & Lecturer/students \\
\hline $\begin{array}{l}40 \mathrm{~min} \\
(275 \mathrm{~min})\end{array}$ & Tumors & $\begin{array}{l}\text { Case study: } \\
\text { SCCHN tongue / oral floor } \\
\text { SCCHN alveolar crest }\end{array}$ & Lecturer/students \\
\hline $\begin{array}{l}45 \text { min } \\
(320 \mathrm{~min})\end{array}$ & Break & & \\
\hline $\begin{array}{l}120 \text { min } \\
(440 \mathrm{~min})\end{array}$ & $\begin{array}{l}\text { Ligature of } 8 \\
\text { taking tissue sampla BLS }\end{array}$ & Practical exercises & Lecturer/students \\
\hline $\begin{array}{l}5 \text { min } \\
(445 \mathrm{~min})\end{array}$ & Break & & \\
\hline $\begin{array}{l}25 \text { min } \\
(470 \mathrm{~min})\end{array}$ & Cranio-maxillofacial emergencies & Buzz-groups & Lecturer/students \\
\hline $\begin{array}{l}10 \min \\
(480 \mathrm{~min})\end{array}$ & Conclusion & Take Home Message & Lecturer \\
\hline
\end{tabular}

Figure 1. Blueprint for the CMF-surgery module 
Examination

Examiner:

Student Information

\begin{tabular}{|c|c|c|c|c|}
\hline \multicolumn{2}{|c|}{ Examination } & $\begin{array}{l}\text { Not } \\
\text { attempted } \\
0\end{array}$ & $\begin{array}{l}\text { Attempted/Incomplete } \\
1\end{array}$ & $\begin{array}{l}\text { Correct/ } \\
\text { Complete } \\
2\end{array}$ \\
\hline \multicolumn{2}{|c|}{$\begin{array}{l}\text { Inspection (Describing the picture): monocle } \\
\text { hematoma, anisocoric, nasal deviation, } \\
\text { flattening/interruptions, swelling - if } 3 \text { and more } \\
\text { pathologies are mentioned } 2 \text { points }\end{array}$} & $\square$ & $\square$ & $\square$ \\
\hline \multirow[t]{3}{*}{ Eye } & Pupils & $\square$ & $\square$ & $\square$ \\
\hline & Vision & $\square$ & $\square$ & $\square$ \\
\hline & Double vision & $\square$ & $\square$ & $\square$ \\
\hline \multirow[t]{2}{*}{ Nerves } & Trigeminal & $\square$ & $\square$ & $\square$ \\
\hline & Facial & $\square$ & $\square$ & $\square$ \\
\hline Skull & Skull cap & $\square$ & $\square$ & $\square$ \\
\hline \multirow[t]{5}{*}{ Midface } & Orbital margin & $\square$ & $\square$ & $\square$ \\
\hline & Zygomatic bone & $\square$ & $\square$ & $\square$ \\
\hline & Le Fort I & $\square$ & $\square$ & $\square$ \\
\hline & Le Fort II & $\square$ & $\square$ & $\square$ \\
\hline & Le Fort III & $\square$ & $\square$ & $\square$ \\
\hline \multirow[t]{3}{*}{ Nose } & Mobility & $\square$ & $\square$ & $\square$ \\
\hline & Inhibition of breathing & $\square$ & $\square$ & $\square$ \\
\hline & Septal hematoma & $\square$ & $\square$ & $\square$ \\
\hline \multirow[t]{5}{*}{ Lower jaw } & Mandibular condyle & $\square$ & $\square$ & $\square$ \\
\hline & Collum/mandibular joint & $\square$ & $\square$ & $\square$ \\
\hline & Mandibular margin & $\square$ & $\square$ & $\square$ \\
\hline & Compression(chin) & $\square$ & $\square$ & $\square$ \\
\hline & Motility lower jaw & $\square$ & $\square$ & $\square$ \\
\hline \multirow[t]{4}{*}{ Intraoral } & Oral inspection & $\square$ & $\square$ & $\square$ \\
\hline & Occlusion & $\square$ & $\square$ & $\square$ \\
\hline & Loose teeth & $\square$ & $\square$ & $\square$ \\
\hline & Opening of the mouth & $\square$ & $\square$ & $\square$ \\
\hline
\end{tabular}

Figure 2. OSCE Checklist CMFS - Head and Skull Examination

Ligature of 8

Examiner:

Student Information

\begin{tabular}{l|l|l|l}
\hline 8er-Ligatur & $\begin{array}{l}\text { Not } \\
\text { attempted } \\
0\end{array}$ & $\begin{array}{l}\text { Attempted } \\
\text { incomplete } \\
1\end{array}$ & $\begin{array}{l}\text { Correct/ } \\
\text { incomplete } \\
2\end{array}$ \\
\hline Teeth correctly identified & $\square$ & $\square$ & $\square$ \\
\hline $\begin{array}{l}\text { "Tongue" traumatized (wire put through the opposite } \\
\text { side) }\end{array}$ & $\square$ & $\square$ & $\square$ \\
\hline One wire above/below the outer one & $\square$ & $\square$ & $\square$ \\
\hline Twisted ,under pull“(not just sole rotary motion) & $\square$ & $\square$ & $\square$ \\
\hline $\begin{array}{l}\text { Proper placement of the ligature (outer wire becomes } \\
\text { "pulled" interdentally) }\end{array}$ & $\square$ & $\square$ & $\square$ \\
\hline Wire-ends shortened & $\square$ & $\square$ & $\square$ \\
\hline Wire-ends bent & $\square$ & $\square$ & $\square$ \\
\hline Tools used (wire scissors, luniartschek, tweeters) & $\square$ & $\square$ & $\square$ \\
\hline $\begin{array}{l}\text { Model lifted no }=2,1 \mathrm{x}=1, \text { multiples times/out of the } \\
\text { green area }=0\end{array}$ & $\square$ & $\square$ & $\square$ \\
\hline
\end{tabular}

Figure 3. OSCE Checklist CMFS - ligature of 8. 
口TA

-Control

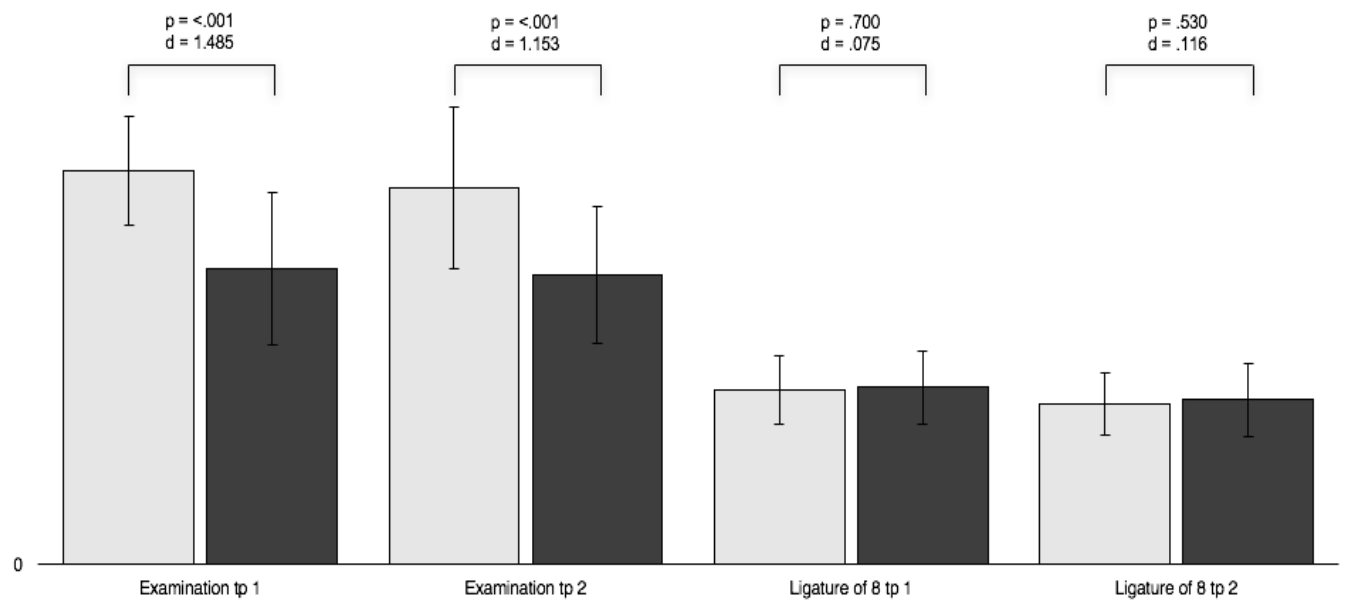

Figure 4. Group analysis timepoint 1 and 2 (tp1 \& 2) - light grey - intervention group; dark grey - control group; achievable max. points examination 48, achievable max. points ligature 18 . 